\title{
Erratum to: Next-generation genomic shotgun sequencing indicates greater genetic variability in the mitochondria of Hypophthalmichthys molitrix relative to $H$. nobilis from the Mississippi River, USA and provides tools for research and detection
}

John J. Miller • Michael S. Eackles •

Jay R. Stauffer • Tim L. King

Published online: 1 November 2014

(C) Springer Science+Business Media Dordrecht 2014

\section{Erratum to: Conservation Genet Resour}

DOI 10.1007/s12686-014-0296-3

In the original publication, the author's funding information was inadvertently omitted. The missing funding information in the acknowledgement section should read as "Partial funding for this document is provided by Great Lakes Restoration Initiative Program grant Award \#F12AP01160 from the U.S. Department of Interior, Fish and Wildlife Service."

The online version of the original article can be found under doi:10. 1007/s12686-014-0296-3.

J. J. Miller $(\bowtie) \cdot$ J. R. Stauffer

School of Forest Resources, Pennsylvania State University,

University Park, PA 16802, USA

e-mail: millerjohnjames.miller@gmail.com

J. J. Miller · M. S. Eackles · T. L. King

Aquatic Ecology Branch, U. S. Geological Survey, Leetown

Science Center, 11649 Leetown Road, Kearneysville,

WV 25430, USA 